\title{
The Uncogent Auxiliary Hypotheses of Gordon and Modugno: Reply to a Review
}

\section{J C Lester}

(As the text indicates in various places, a version of this essay is now a chapter in a book: Lester, J. C. 2014. Explaining Libertarianism: Some Philosophical Arguments. Buckingham: The University of Buckingham Press.)

\section{Prefatory Note}

Lester's reply to the review ${ }^{1}$ by Gordon and Modugno of Escape from Leviathan ${ }^{2}$ was due to appear in a later edition of the same periodical, but it was eventually dropped without notice or a reason being given. ${ }^{3}$ Subsequently, their review has occasionally been cited in isolation as a refutation of that book's theory of liberty, the compatibility of such liberty with welfare maximisation, and the use of "Popperian views" - as though a complete reply did not exist and were not freely available and easily found online. To make it harder to avoid the reply, whether by accident or design, it is reproduced here (but with sundry small emendations for greater clarity).

\section{Reply}

David Gordon and Roberta A. Modugno (G\&M) begin by providing, at least initially, a useful and accurate brief exposition of Escape from Leviathan (EFL). It is agreeable to have one's theories be generally understood and it makes being criticised much more productive. However, thereafter things go downhill rapidly. G\&M go on to suggest that "People often do not like to surrender their pet views even when evidence seems to show them false" (102). All people have some views that they both think true and value. But to refer to these as "pet views" is at least suggestive of being an ad hominem. It is ostensibly, and erroneously, to imply that such views ought therefore to be taken less seriously by others. Also, if the evidence really seemed to people to show their own views to be false, then how could they continue to hold those views? G\&M appear to be implying that people can partly choose what they believe. That view has long seemed a false one to me, and a view that has the unfortunate consequence of stopping debate on the supposition that it is futile to argue against beliefs thus held (indeed, it would be futile to debate if we could choose what we believed).

Now, if we are to try to explain away anomalous evidence (and surely we should do so, for evidence itself needs to be tested and criticised), then presumably we might "devise an auxiliary hypothesis." There cannot be anything wrong with this unless the auxiliary hypothesis is false,

${ }^{1}$ Gordon, David and Modugno, Roberta A. 2003. Journal of Libertarian Studies 17, 4: 101-109.

${ }^{2}$ Lester, J. C. [2000] 2012. Escape from Leviathan: Libertarianism without Justificationism. Buckingham: The University of Buckingham Press.

${ }^{3}$ However:

Articles Accepted for Publication ... JLS 24 - J.C. Lester (reply) The Uncogent Auxiliary Hypotheses of Gordon and Modugno Received 1/21/05 Ref: to run in same issue with response by David and Roberta (Google search on 16 October 2014)

Presumably, they did not respond and so it was thought better to surreptitiously spike Lester's reply so that it looked as though EFL was refuted and the author unable to answer. 
irrelevant, or - as G\&M suggest - it makes the combined hypothesis go "too far" (even all the way) towards making it "immune from refutation" (102-103). Thus the argument will be, at least, not cogent. G\&M attempt to show that EFL does often go "too far." They also propound the views that $E F L$ has unsound theories of 1) liberty, 2) such liberty's compatibility with preference-utilitarianwelfare maximisation, and 3) "Popperian views" and their application. The response here is that it is G\&M who come up with one "convenient auxiliary hypothesis" (106) after another to try to defend their views - and without ultimate success, as will be seen.

G\&M next note the defence of a priori rationality. They wonder how consistent this is with "other parts of his project" (103). It is true that I state and explain that - as G\&M put it - "there are logical connections between liberty and welfare that can be known a priori." It does not follow that this is inconsistent with the "Popperian view that one's theory is, at best, a conjecture that has survived testing." Despite the explanation in EFL's very brief introductory chapter, G\&M have mistaken Popper's scientific epistemology (requiring the possibility of empirical falsification, which they explain) with his, later, generalised critical rationalist epistemology (that all theories are conjectures that we should criticise as best we can but cannot usefully attempt to support). Thus to argue that there are some a priori connections between liberty and welfare does not entail that these have been, or can be, given positive epistemological support. It is only to try to show that they withstand criticism as far as we can tell. Critical rationalism does not rest "on the contention that nature does not disclose necessary relations to us." Critical rationalism can accept that there are "necessary relations" in mathematics, for instance, but says this does not mean we can avoid having to conjecture proofs that might turn out eventually to be faulty (as Leonard Euler, 1707-1783, showed was true in various cases).

That said, it is hard to see how there are "necessary relations" in "nature" in the sense of the physical world or how 'she' might "disclose" them to us. Nor is it right that "philosophy is an a priori discipline" tout court. Philosophical problems are often affected by advances in science and technology. ${ }^{4}$ We would not expect that if it were purely a priori. My current view of the a priori is that it is a matter of degree and not always clear. The a priori aspects of rationality, for instance, come down to very general truths that we can assume without testing or criticising them at every turn (although doing so occasionally is fine). For example, it is conceivable that (other) human beings are not agents at all but unconscious, or that some agents make perverse utility choices (somehow choosing what gives them less utility at that moment), or that people's limbs do not move as they choose, etc. If any of these things were typically, or even often, true then economics as a discipline explaining the human world might be in trouble (in its current form, at least). But such bizarre assumptions do not withstand criticism or testing (as is argued of sundry similar assumptions in the chapter on rationality in $E F L$ ). If it seems to some people that this is to deny - at least in economics that there really are a priori truths, then we could drop that expression with anyone who felt that way. However, it is a very useful expression and some near equivalent would be needed to replace it (perhaps the humorous 'translation' of knowing some things 'armchairiori'). I should also add perhaps at risk of appearing too pedantic - that philosophy itself is not really a "discipline": it is too fundamental and diverse to have the structure of a discipline.

G\&M state that "Mises does not claim that everyone is out to maximize certain pleasant sensations, or minimize painful ones" but that "Lester maintains exactly that" (104). This is more or less the opposite of the truth. Mises sometimes at least appears to slide into this error, as I point out in EFL (16):

\footnotetext{
${ }^{4}$ Moreover, as philosophy and science were not distinct intellectual pursuits up to Galileo Galilei's time, then progress in one could be held to be progress in both.
} 
Strictly speaking the end, goal, or aim of any action is always the relief from a felt uneasiness. (Human Action, $9^{5}$ )

What a man does is always aimed at an improvement of his own state of satisfaction. (Ibid, 242)

By contrast, I take pains to avoid this error. I do indeed state that "What [not 'When' as G\&M have it] one desires or wants to do, one has utility (felt satisfaction, in a very general sense) at the thought of having, achieving, or doing. This requires conscious ... desires to motivate us as agents" $(E F L, 47)$. But I argue that such utility cannot be reduced to hedonism, eudaemonism, or psychological egoism. The course of action that we find most 'satisfying' might be some terrible duty. Nevertheless, it must somehow vie with other possibilities and satisfy our desires at that time more than any alternative action. Or why would we choose it?

G\&M ask why if someone purchases a loaf of bread "his act of purchase be accompanied by feelings, e.g., anticipatory hunger pangs?" I do not suggest that anything like "anticipatory hunger pangs" are necessary, only that some feeling must be. They ask, "Why is it not enough if one recognizes a reason to act in a certain way?" And the answer is that one must feel that it is a sufficient reason - and better than any perceived alternative. I can recognise or understand that something is a reason without feeling motivated by that reason. By analogy, I can recognise or understand a theory without the feeling that it is true. Only our feelings can change intellectual apprehensions into actual desires and beliefs. However, these feelings can be David Hume's "quiet passions" - especially if there is not much to compete with them at the time. And so they might mistakenly be assumed to be 'pure reason' motivating or persuading us. Like Hume, I cannot see how pure reason could do this. I do not think, as G\&M imply I require, that it is "part of the concept of action that feelings must always direct a choice." But then I tend to follow Popper in thinking that conceptual analysis is not very useful in solving real philosophical problems.

Although my explicit theory of liberty is "very different from that held by most libertarians" (105), I assert that it is what libertarians implicitly hold or at least require. I do not, of course, see how liberty could coherently be theorised "by reference to coercion" because in the plain English sense 'coercion' (the use or threat of force to compel behaviour) is neither necessary nor sufficient to make an act unlibertarian. However, that G\&M see my theory of liberty as "At first glance ... grossly mistaken" is undoubtedly partly due to explanatory failure on my part. ${ }^{6}$

G\&M look at my discussion of Salman Rushdie's offending many millions of Muslims. Perhaps a similar kind of problem arises in principle if, as they suggest, we simply make their auxiliary assumption that "a large number of Muslims was upset by the mere fact that he did not adhere to that religion." But that is not "Exactly the same problem." This is because there are billions of people who might upset Muslims in this way. Still, we can ignore the improbability of their auxiliary assumption and assume that, somehow, it is only Rushdie that is causing such annoyance. How does this "eliminate the issue of provocation by the minority" (emphasis added)? Why are the Muslims not 'provoked' just because Rushdie "did not adhere to that religion"? Provocation seems to be at least partly in the eye of the beholder. That said, I don't see that anything relevant hangs on this.

I certainly do not make a "distinction between harm and benefit" (as G\&M state I do). My distinction is between cost and benefit. I explain that 'harm' is hopeless for the job, as it is libertarian to objectively harm people with their permission and it is not libertarian to save people from objective

\footnotetext{
${ }^{5}$ Mises, Ludwig Edler von. [1949] 1966. Human Action: A Treatise on Economics. 3rd rev. ed. Chicago: Henry Regnery Co.

${ }^{6}$ There are now clearer explanations of it throughout many of the other chapters of this book.
} 
harm against their wishes (EFL, 59-60). Can G\&M show that my distinction between cost and benefit "faces collapse"? They state that "In ordinary terms ... Rushdie's failure to profess the Muslim faith ... fails to confer the benefit they would obtain were he to join them. But if the Muslims find upsetting Rushdie's refusal ... they are harmed." I would explain this rather differently in EFL terms. I am not really interested in how this might be put in "ordinary terms" but how the assumed theory of liberty is correctly applied here; it might well flout common sense. If Rushdie's non-Islamic status means that Muslims thereby have lower utility than if Rushdie did not exist, then his existence is an initiated imposed cost to the Muslims. Whether his conversion would, contingently, only remove this cost or also be a positive benefit does not alter this fact. Thus my, pre-propertarian, cost-benefit theoretical distinction is not threatened by this example. (And economics can continue to use its analogous, propertarian, cost-benefit distinction too.)

Nor is it correct that "Lester recognizes this point" when I say that "Others' benefits impose no cost on us except insofar as we feel unavoidably covetous or envious" (EFL, 77). It is not Rushdie's benefits that are imposing a cost by his not being Islamic. G\&M mention 'my' example that, in their words, "someone's failure to share water from his well makes his covetous neighbor upset, thus harming him. Here precisely the failure to benefit someone becomes a harm to that very person" (106). More accurately, my main example was that you do not impose a cost (not "harm") by producing and monopolising a well, with the qualification "except insofar as we feel unavoidably covetous or envious" (and that these emotions are usually not unavoidable but largely self-inflicted). However, let us again grant G\&M's auxiliary hypothesis and even assume that there are some serious and systematic examples where failing to benefit someone is itself primarily what imposes on him, through unavoidable envy or lust or whatever. That would still not show that benefits and costs theoretically collapse into each other. Rather, they would be examples of particular practical inseparabilities. They would not vitiate the theoretical distinction or, of course, all cases where they can in practice be separated.

G\&M find "weak" my quoted argument that "people can more or less control their emotional response to mere opinions - especially in the long term. The angry Muslims more or less chose to react angrily." Lester has "simply helped himself to a convenient auxiliary hypothesis." Yes, that is right. We ought to help ourselves to convenient auxiliary hypotheses as freely as our imaginations can allow. As I said at the start, this is only a mistake if they are not true, or relevant, or make the thesis less falsifiable. It is positively desirable if someone "produces out of thin air a hypothesis that, he hopes, will defuse the counterexample." Putative counterexamples need themselves to be criticised. And all hypotheses are ultimately unsupportable (but not untestable or uncriticisable) assumptions that come "out of thin air" (our imaginations). This is clearly not to "render [my] conception immune from falsification." It is merely to argue that a particular attempted falsification does not work for the reason given.

I do not see how my reply to the criticism using an "auxiliary hypothesis" makes my original conjecture "less bold." Suppose I conjecture that there are no talking dogs. G\&M suggest that there is a well-known talking dog in Alabama. I go to Alabama to check and discover that this appears to be, rather, a very clever ventriloquist act. My "auxiliary hypothesis" reply to G\&M does not make my original conjecture one whit less bold. The auxiliary hypothesis that a particular putative counterexample is a clever ventriloquist act does not modify the original conjecture. I continue to conjecture that dogs cannot talk "simpliciter." Of course, if an 'auxiliary hypothesis' is defined as being one that modifies the original conjecture, then I deny that I have made one (but that was not what G\&M originally claimed). G\&M then "suggest as a criterion for an auxiliary hypotheses [sic] that it itself be a conjecture that has survived testing." From a falsificationist perspective, it is utterly irrelevant that a conjecture has withstood tests thus far; only a justificationist would think that relevant. It is only relevant that it is testable. And in broader critical rationalist terms, it need only be 
criticisable. My, initial, point that people have some considerable control over their emotional responses is quite criticisable. There are all sorts of things one might say against it (although I, naturally, conjecture that they will not suffice to refute it). So my reply meets critical rationalist requirements, and it would be faulty if it tried to live up to G\&M's justificationist requirements.

Eventually, G\&M get around to criticising the actual argument instead of mistakenly arguing that it is epistemologically illegitimate. First they say that "Contrary to what [Lester] says, it seems to us that emotional responses to opinions often resist efforts to alter them" (106-107). But the Muslims did not need to make "efforts" to alter their emotional responses. They needed only to stop making efforts to work themselves into a frenzy, partly at the behest of their religious leaders (the 'anger' was a sham put on out of duty to religion). G\&M do not deny that, as I put it, "they more or less chose to react angrily." And that is the practical point in this example. For the sake of argument, G\&M grant that the Muslims can control their emotions about Rushdie and his book. They ask why they are obligated to do so in order to minimise imposed costs, as the "principle says nothing about people having to change their views about harms [i.e., costs] to them." But the principle is supposed to be as abstract as possible. Therefore, of course, it does not specify how it is to be interpreted in practice. The principle says nothing explicit about even such basic things as self-ownership or how private property is acquired. These relations are what I was trying to derive.

More relevantly, G\&M go on to ask whether requiring people to become vegetarian would be "required by liberty, if it turns out that meat eaters could easily alter their preferences about food, but vegetarians cannot expunge their feelings of revulsion at the thought that some people eat meat." If done "easily" enough relative to unavoidable and great enough "revulsion", then the strict answer is 'yes' (although perhaps with compensation payable that is half way between the alternative imposed costs to each side). The main reason that this is counterintuitive to our notions of what is acceptable and liberal is that people are not at all like this. In reality, the typical meat eater delights in his diet and would miss it hugely (I write having returned rather disappointed from a luncheon invitation that turned out to be vegetarian) while the typical vegetarian clearly does not have a comparably strong feeling of disgust at the mere thought of someone else eating meat and, in any case, he does not need to think about it. So G\&M have here exactly the kind of fantasy criticism (which, following R. M. Hare, I discuss in EFL especially with respect to preference utilitarianism) that our intuitions have not evolved or been accustomed to deal with. However, suppose we take a more realistic analogy (and one I use in $E F L$ ). Is requiring people to respect land ownership consistent with liberty if it turns out that nomads can relatively easily alter their preferences but settlers cannot expunge their feelings about the extreme disutility of not being able to settle and protect land? Yes it is, and that is the world we live in. But things might be different if the vast majority of people were naturally and fiercely nomadic with the minority having a weak preference for settling.

G\&M then suggest that even allowing for "controllable" preferences it might "be easier to induce Rushdie to curb his (surely voluntarily adopted) preference for writing novels designed to provoke his readers than to demand that several million Muslims change their reactions." And if that is all that the choice ultimately involves (Rushdie versus vast Muslim disapproval in a one-off situation) then perhaps Rushdie should curb his preferences to write such novels. But my argument on self-control was not supposed to stand alone in such an abstract setting. It is merely the first point I make before bringing in more realistic aspects. My so-called "second response" about the general consequences of giving in to those who are upset at what others are communicating about is another part of the whole case. G\&M think it is possible to limit the rule simply to examples where "a very large number of people are greatly upset by the statements made by one person." Let us yet again grant them this "convenient auxiliary hypothesis" (but in reality there are surely also many who value hearing such a person, and his views are almost always very far from unique: he is simply a well-known proponent). This still creates a dictatorship of the majority against anyone who the mass media currently makes 
into a scapegoat. Free communication is undermined where it is most valuable: the lone voice with a different view. What better way to stop all intellectual progress. Even in science a novel theory will sometimes annoy a lot of scientists. Thus in the long term the suppression of such free communication looks likely to impose greater cost than toleration does.

However, G\&M then allow for the sake of argument that "a limited principle of suppression of offensive speech would, in time, collapse into an unacceptable rule" (107-108). They then "help themselves' to another auxiliary hypothesis: that a "natural reading" of minimising imposed costs is that it be applied not with regard to the long term consequences, but "at that time." I make clear and argue in EFL that imposed costs cannot reasonably be restricted to the immediate circumstances or even to what people are consciously aware of (it is sufficient that something flouts what someone values: e.g., an unknown theft or even trespass is still an imposed cost). Therefore, I cannot see why it should matter what is the "natural reading" - even if we grant G\&M's auxiliary hypothesis that it is the "natural reading." However, supposing that imposed costs refer only to the immediate circumstances is as perverse as thinking that a utilitarian calculation would "naturally' refer to only the immediate circumstances (i.e., rejecting rule utilitarianism). And, in any case, how immediate is "at that time"? The next few seconds, hours, days? G\&M think that I at least "owe" them "some account of how present and future consequences of a policy are to be assessed." The short answer is that it will be by conjecture and criticism. How else? I cannot, of course, 'justify' this view. Putting the general issue in a realistic scenario, do G\&M really think that any long-term policy of forcibly suppressing freedom of communication or belief could be a lesser cost imposition than the discomfort of occasionally realising that some people are thinking or believing things of which one strongly disapproves? As I cannot see how this is likely, I cannot see a realistic problem with the theory of liberty I am defending and applying.

Of my account of welfare, G\&M state that "Lester, unlike Mises and Rothbard, maintains that interpersonal comparisons of utility are possible." This bald statement is seriously misleading. My position, as explained and defended in $E F L$, includes the following theses: 1) we cannot help making some rough and ready comparisons of utility; 2) without these we would not be able to make proper sympathetic sense of individual and social circumstances; 3 ) we are not really comparing the same thing, especially when it comes down to details; 4) we certainly cannot compare utility in any 'scientific' detail sufficient to have planning; 5) granting approximate plausible interpersonal utility comparisons (at least ad arguendo) leads us back to libertarian policies in practice; and 6) merely dismissing all utility comparisons as nonsense, leaves libertarians in a very weak rhetorical position and appearing callous with it.

G\&M offer a "key objection" to my thesis that minimising imposed costs and maximising welfare are congruent in practice. This is along similar lines to their previous auxiliary hypothesis. They posit that the Muslims "dissipate their angry feelings toward Rushdie" so he lives without imposing costs. However, "the Muslims would be made extremely happy by Rushdie's demise ... their total satisfaction outweighs Rushdie's reluctance to give up his life" (109). Thus, "minimizing imposed costs and maximizing welfare lead to different results" and my "account of welfare, taken by itself, leads to a counterintuitive outcome, so it also stands refuted." First, a "counterintuitive outcome" is not a refutation. Indeed, if an argument is sound then the truth of the counterintuition is refuted. But my compatibilist thesis (reconciling liberty, welfare, and anarchy) is explicitly stated at the start of $E F L$, and repeated throughout, to be about realistic and long-term effects. G\&M recognise my likely reply from another example I use: "We would have to appeal to the indirect consequences of allowing any sufficiently large majority to persecute a sufficiently small minority" $(E F L, 159)$. And once more G\&M simply help themselves to the convenient auxiliary hypothesis that "Once more, Lester has simply helped himself to a convenient auxiliary hypothesis." They say that without "certain assumptions about indirect consequences" my thesis would appear to be false. So they "may regard as 
true these assumptions about indirect consequences" but the thesis is damned for being "a textbook case of what Popper terms an immunization strategy." No, that is not an immunization strategy. I am not adding assumptions that effectively mean the thesis cannot be falsified. I am merely citing a reason that it is not falsified. And to grant the "indirect" defence, as they do, is ipso facto to concede that it is defended. There is nothing illegitimate about appealing to the indirect and long-term consequences unless I am mistaken about these. Again, in a realistic long-term situation (which is what I state my compatibility thesis is about: not singular or imaginary cases), do G\&M really believe that it is on balance a less cost-imposing principle to allow any majority to persecute or murder any single person they merely dislike?

Overall, I feel that G\&M have made some points that have at least prompted me usefully to clarify my ideas to some extent. ${ }^{7}$ But if they had read more carefully and not kept raising the erroneous point about auxiliary hypotheses (to which they rightly, but inconsistently and irrelevantly, helped themselves), then they might have focussed on and criticised the arguments more cogently.

${ }^{7}$ Elucidations of several of the main theories and arguments can now be found in the other chapters of this book. 